\title{
Effects of different drying methods on the proximate composition and antioxidant activities of Ocimum basilicum leaves
}

\author{
Siti Mahirah, Y., *Rabeta, M.S. and Antora, R.A. \\ Food Technology Division, School of Industrial Technology, Universiti Sains Malaysia, Minden, Gelugor- \\ 11800, Penang, Malaysia
}

\author{
Article history: \\ Received: 14 March 2018 \\ Received in revised form: 14 \\ April 2018 \\ Accepted: 27 April 2018 \\ Available Online: 17 May \\ 2018
}

Keywords:

Drying methods,

Proximate analysis,

Antioxidant activities,

Ocimum basilicum

DOI:

https://doi.org/10.26656/fr.2017.2(5).083

\section{Introduction}

Ocimum basilicum, or "selasih" by the locals, is one kind of herb which is widely found in Malaysia. It is usually consumed as "ulam" or as an ingredient in Malaysian dishes because of its strong and fragrant aroma. O. basilicum is an annual herb, which grows in several regions around the world, with more than 150 species of the genus Ocimum (Naidu et al., 2016). According to Tewari et al. (2012), illnesses including common colds, headaches, stomach disorders, inflammation, heart disease, various forms of poisoning, and malaria could be treated by Ocimum family extracts, which are used in Ayurvedic remedies.

Selasih or basil tea is good for treating dysentery, nausea and flatulence, vomiting, constipation, mental fatigue, and cough (Marwat et al., 2011; Ch et al., 2015). It can cure toothache, earache, and epistaxis or nosebleed when used with camphor (Ch et al., 2015). Selasih seeds are also edible and become gelatinous when exposed to water. These seeds are normally consumed with flavored drink by the locals. Selasih seeds also have medicinal effects to treat fever given that it can cool down body temperature. According to Ch et al. (2015), infused water of selasih seeds can treat gonorrhea, chronic diarrhea, and dysentery.

Chemical spoilage occurs when food products undergo oxidation. Spoilage affects food nutritional quality, safety, flavor, odor, and appearance, i.e., color and texture (Antolovich et al., 2002). An excessive production of free radicals in organisms leads to many health problems, such as aging, cancer, atherosclerosis, diabetes, stroke, and inflammatory disorders (Thorat et al., 2013). Antolovich et al. (2002) stated that antioxidants are generally divided into two classes, primary and secondary antioxidants, respectively. This study was conducted to assess the effects of different extraction and drying methods on the antioxidant capacity, total phenolic and flavonoids in $O$. basilicum leaves.

\section{Materials and methods}

\subsection{Sample collection and preparation}

Fresh O. basilicum leaves without any physical damage were collected from Bukit Mertajam, Pulau 
Pinang. The fresh leaves were separated from the plant and washed under running tap water followed by drying at room temperature for 5-6 hours to remove all of the remaining water. The first batch was used as fresh sample for solvent extraction. Another batch was dried using vacuum oven (Binder Vacuum-Oven, Germany) at $30^{\circ} \mathrm{C}$ for 4 days. The third batch was dried using freeze dryer (Labconco, New York) at $-50^{\circ} \mathrm{C}$ for 3 days. The initial weight of each batch of samples was about $450 \mathrm{~g}$ of leaves. After drying, the samples were then blended in a normal grinder (Panasonic MX-898M-LW) until fine and sieved. The samples in powder form were sealed in plastic bag, kept in dark, airtight container and stored in a freezer at $-20^{\circ} \mathrm{C}$.

\subsection{Sample extraction}

Extraction of sample was carried out according to the method described by Rabeta and Lai (2013). Approximately, $1 \mathrm{~g}$ of fresh and dried samples (freezedried and vacuum-oven dried) was weighed into a conical flask, wrapped with aluminium foil, and $100 \mathrm{~mL}$ of $80 \%$ methanol was added. The mixture was shaken at $160 \mathrm{rpm}$ and $27^{\circ} \mathrm{C}$ in an Incubator shaker (Lab Companion, SI600R) for $24 \mathrm{~h}$ and then centrifuge (Kubota Corporation, model 4000 ) for $30 \mathrm{~min}$ at $2500 \mathrm{rpm}$ to obtain a clear extract. The same method was repeated by using aqueous ethanol $(80 \% \mathrm{v} / \mathrm{v})$ and distilled water.

\subsection{Proximate analysis}

Proximate analysis of the samples, which include moisture content, ash, crude protein, fat, and crude fiber, was determined according to the methods set forth by the Association of Analytical Chemist (AOAC) (2000). Percentage of carbohydrate content was determined by the following formula:

$\%$ Carbohydrate $=100-($ moisture $\%$ ash $+\%$ fat $+\%$ protein $+\%$ fiber content)

\subsection{Determination of total phenolic content (TPC)}

Folin-Ciocalteu (F-C) assay was used to determine total phenolic compound in sample with slight modification which followed the method by Alothman et al. (2009a). A $400 \mu \mathrm{L}$ aliquot of properly diluted sample extract was mixed with $2 \mathrm{~mL}$ (10 times pre-diluted) Folin-Ciocalteu's reagent. After standing for $5 \mathrm{~min}$ at room temperature, $1.6 \mathrm{~mL}$ of $(7.5 \% \mathrm{w} / \mathrm{v})$ sodium carbonate solution was added. The solutions were mixed and allowed to stand for $1 \mathrm{~h}$ at room temperature. The absorbance was measured at $765 \mathrm{~nm}$ using a UV-visible spectrophotometer (Shimadzu, UVmini-1240). A calibration curve was prepared using a standard solution of gallic acid at $20,40,60,80,100 \mathrm{mg} / \mathrm{L}$ concentration. Results were expressed as mg gallic acid/g sample.

\subsection{Determination of total flavonoid content (TFC)}

Total flavonoid content was determined by using colorimetric assay followed by Kamtekar et al. (2014). About $1 \mathrm{~mL}$ of properly diluted sample extract was mixed with $4 \mathrm{~mL}$ of distilled water. Then, $0.3 \mathrm{~mL}$ of $(5 \%$ w/v) $\mathrm{NaNO}_{2}$ was added. After $5 \mathrm{~min}, 0.3 \mathrm{~mL}$ of $(10 \% \mathrm{w} /$ v) $\mathrm{AlCl}_{3}$ was added. At $6 \mathrm{~min}, 2 \mathrm{~mL}$ of $1 \mathrm{M}$ solution of $\mathrm{NaOH}$ were added. After that, the volume was made up to $10 \mathrm{~mL}$, immediately by the addition of $2.4 \mathrm{~mL}$ of distilled water. The mixture was shaken vigorously and the absorbance of the mixture was read at $510 \mathrm{~nm}$ by using UV-visible spectrophotometer (Shimadzu, UVmini -1240). A calibration curve was prepared using a standard solution of quercetin The results were also expressed on a fresh weight basis as $\mathrm{mg}$ quercetin/g sample.

\subsection{1,1-diphenyl-2-2picrylhydrazyl (DPPH) free radical scavenging assay}

This method was done by followed Tabart et al. (2007) method with slight modification. Stock DPPH solution was prepared fresh by mixing DPPH into methanol at a concentration of $100 \mu$ mole/L. Approximately, $1 \mathrm{~mL}$ of sample extract from solvent extraction was mixed with $6 \mathrm{~mL}$ of DPPH solution. The mixture was vortexed for 1 minute and kept in dark for 30 minutes. Absorbance was read at $517 \mathrm{~nm}$ of wavelength using UV-Vis Spectrophotometer (Shimadzu, UVmini-1240) against blank of methanol. The result obtained was calculated and expressed in the terms of \% DPPH free radical scavenging activity by using the formula that was stated below.

$\%$ Inhibition $=\left[\left(\mathrm{A}_{\text {control }}-\mathrm{A}_{\text {sample }}\right) / \mathrm{A}_{\text {control }}\right] \times 100 \%$

\subsection{Ferric reducing antioxidant power (FRAP) assay}

FRAP assay was performed according to a method described by Benzie and Strain (1996). FRAP reagent was prepared fresh by mixing $300 \mathrm{mM}$ sodium acetate buffer (pH 3.6) with $10 \mathrm{mM}$ 2,4,6-tris (1-pyridyl)-5triazine (TPTZ) solution in $40 \mathrm{mM} \mathrm{HCl}$ and $20 \mathrm{mM}$ $\mathrm{FeCl}_{3} \cdot 6 \mathrm{H}_{2} \mathrm{O}$ in volume ratio 10:1:1. Next, a small amount of properly diluted sample with $200 \mu 1$ volume was mixed with $3 \mathrm{~mL}$ of FRAP reagent. The mixture was then incubated in water bath at $37^{\circ} \mathrm{C}$ for 30 minutes. The absorbance was read at $593 \mathrm{~nm}$ with UV-Vis spectrophotometer (Shimadzu, UVmini-1240) against blank. A calibration curve was prepared by using an aqueous solution of ferrous sulphate $\mathrm{FeSO}_{4} .7 \mathrm{H}_{2} \mathrm{O}(200$, $400,600,800 \mu \mathrm{M})$. FRAP values were expressed on a fresh weight basis as micromoles of ferrous equivalent Fe (II) per gram of sample. 


\subsection{Statistical analysis}

Results were reported as means \pm standard deviation (SD) for triplicate determinations. Analysis of variance (two-way ANOVA) and the significant difference between mean values was determined by using Duncan test at a level of significance of $\mathrm{P}<0.05$. Statistical analyses were conducted by using SPSS 23.0 (SPSS for Window, 2007, SPSS Inc., Chicago, USA).

\section{Results and discussion}

\subsection{Proximate analysis}

Proximate analysis was performed by using fresh, freeze-dried, and vacuum oven-dried samples. The determined parameters were moisture, ash, crude protein, crude fat, crude fiber, and total carbohydrate content. One of the most important parameters considered during storage of dried raw herbal is moisture (Razak et al., 2014). The moisture contents of fresh, freeze-dried, and vacuum oven-dried samples were $86.90 \pm 0.09 \%$, $7.99 \pm 0.08 \%$, and $6.83 \pm 0.11 \%$, respectively $(p<0.05)$ (Table 1). High moisture content in fresh sample decreases the quality of stored samples because the water content in herbs may possibly cause microbial growth (Sospedra et al., 2010). Freeze dried and vacuum ovendried sample results showed that the low moisture content was less than $10 \%$. The low moisture content of food product means long shelf life (Ojo et al., 2014). According to Agoreyo et al. (2011), the low moisture content decreases the perishability and increases the value and shelf life of the food.

Table 1. Proximate composition in leaves of $O$. basilicum

\begin{tabular}{lccc}
\hline \multirow{2}{*}{ Samples } & \multicolumn{3}{c}{ Leaves of O. basilicum } \\
\cline { 2 - 4 } & Fresh & $\begin{array}{c}\text { Freeze } \\
\text { Dried }\end{array}$ & $\begin{array}{c}\text { Vacuum- } \\
\text { oven Dried }^{\mathrm{c}}\end{array}$ \\
\hline Moisture (\%) & $86.90 \pm 0.09^{\mathrm{a}}$ & $7.99 \pm 0.08^{\mathrm{b}}$ & $6.83 \pm 0.11^{\mathrm{c}}$ \\
Ash (\%) & $2.08 \pm 0.12^{\mathrm{c}}$ & $12.83 \pm 0.05^{\mathrm{b}}$ & $15.05 \pm 0.29^{\mathrm{a}}$ \\
Protein (\%) & $3.22 \pm 0.03^{\mathrm{b}}$ & $18.72 \pm 0.83^{\mathrm{a}}$ & $18.60 \pm 0.63^{\mathrm{a}}$ \\
Fat (\%) & $4.85 \pm 1.22^{\mathrm{b}}$ & $5.30 \pm 0.20^{\mathrm{a}}$ & $5.86 \pm 0.40^{\mathrm{a}}$ \\
$\begin{array}{l}\text { Crude Fibre } \\
(\%)\end{array}$ & $7.98 \pm 0.49^{\mathrm{c}}$ & $8.36 \pm 0.32^{\mathrm{b}}$ & $9.89 \pm 0.18^{\mathrm{a}}$ \\
$\begin{array}{l}\text { Carbohydrate } \\
(\%)\end{array}$ & $5.03 \pm 1.68^{\mathrm{c}}$ & $46.80 \pm 0.83^{\mathrm{a}}$ & $43.78 \pm 0.51^{\mathrm{b}}$ \\
\hline
\end{tabular}

Values are means $\pm S D(n=3)$. For each row, values followed by the different letter are significantly difference at $(\mathrm{P}<0.05)$

The ash content in fresh samples was lower $(2.08 \pm 0.12 \%)$ than those of freeze-dried $(12.83 \pm 0.05 \%)$ and vacuum oven-dried samples $(15.05 \pm 0.29 \%)$. The ash content was significantly different among the three groups $(\mathrm{P}<0.05)$. Vacuum oven-dried samples obtained the highest ash content among the samples. In addition, the samples showed a significant increase in ash content after drying due to water removal, thereby increasing the nutrient concentration (Morris et al., 2004). Moreover, the increased ash content after drying can also be explained by the low volatility of minerals, which are not destroyed by heating. The ash content represents the total amount of minerals present in a food (Agoreyo et al., 2011).

Furthermore, the protein contents in freeze-dried and vacuum oven-dried samples were $18.72 \pm 0.83 \%$ and $18.60 \pm 0.63 \%$, respectively. No significant difference was observed between these two samples $(\mathrm{P}>0.05)$. Ojo et al. (2014) also studied the protein content in different types of drying and detected no significant difference between sun-dried and solar-dried and fortified fufu flour. This result showed that the protein content in Ocimum basilicum is remarkably retained using these two drying methods (Ojo et al., 2014). Nevertheless, a significant difference was observed between fresh and dried samples $(\mathrm{P}<0.05)$. Fresh samples obtained the least protein content among the three samples (3.22 $\pm 0.03 \%)$. This result can be explained by high water content in the food matrix, which decreased the nutrient concentration (Morris et al., 2004)

The fat contents in fresh, freeze-dried, and vacuum oven-dried samples were $4.85 \pm 1.22 \%, 5.30 \pm 0.20 \%$, and $5.86 \pm 0.40 \%$, respectively. No significant difference $(\mathrm{P}>0.05)$ was observed between freeze- and vacuumoven dried samples; on the contrary, a significant difference was detected between fresh samples and the freeze- and vacuum-oven dried samples. The fat content in food matrix can be related to the oxidative rancidity, which may affect the storage life of food (Ojo et al., 2014). Human dietary fiber comes from plant sources, such as fruits, vegetables, and seeds. Crude fiber is a measure of cellulose, hemicellulose, and lignin (Ogunlakin et al., 2012). A significant difference in crude fiber content $(\mathrm{P}<0.05)$ was observed among fresh sample $(7.98 \pm 0.49 \%)$, vacuum oven-dried sample $(9.89 \pm 0.18 \%)$, and freeze-dried sample $(8.36 \pm 0.32 \%)$, with the fresh sample containing the lowest fiber content, and vacuum-oven sample showed the highest fiber content. Agunbiade et al. (2015) recorded 10\% of the crude fiber in basil in their study; this result is close to the value obtained in the current study $(<10 \%)$. Crude fiber benefits people by aiding in peristalsis movement of foods, helping in bowel movement, lowering blood cholesterol, and reducing the risk of colon cancer (Ojo et al., 2014)

\subsection{Total phenolic content (TPC)}

Table 2 shows that the highest TPC was recorded in freeze-dried samples with methanol extract $(54.46 \pm 1.24$ $\mathrm{mg}$ gallic $\mathrm{acid} / \mathrm{g}$ ), freeze-dried samples in ethanol 
(45.40 $\pm 1.01 \mathrm{mg}$ gallic acid $/ \mathrm{g}$ ), vacuum-dried samples with methanol extract $(38.26 \pm 1.65 \mathrm{mg}$ gallic acid $/ \mathrm{g})$, vacuum oven-dried samples with ethanol extract (32.68 $\pm 0.06 \mathrm{mg}$ gallic acid $/ \mathrm{g})$, freeze-dried samples with water extract $(26.23 \pm 0.63 \mathrm{mg}$ gallic acid $/ \mathrm{g})$, vacuum oven-dried samples with water extract $(21.67 \pm 1.19 \mathrm{mg}$ gallic acid/g), fresh samples with methanol extract $(3.84 \pm 0.33 \mathrm{mg}$ gallic acid $/ \mathrm{g})$, fresh samples with water extract $(3.41 \pm 0.77 \mathrm{mg}$ gallic acid $/ \mathrm{g})$, and fresh samples with ethanol extract $(2.61 \pm 0.33 \mathrm{mg}$ gallic acid $/ \mathrm{g})$ sequentially. In general, the results showed a significant difference $(\mathrm{P}<0.05)$ among the fresh, vacuum-oven, and freeze-dried samples and among the three types of extraction solvents, such as $80 \%$ methanol, $80 \%$ ethanol, and water. However, no significant difference $(\mathrm{P}>0.05)$ was observed among fresh samples for all three different types of solvents.

Table 2. Total phenolic content (mg gallic acid/g) of the samples by using different extraction solvent and drying method

\begin{tabular}{lccc}
\hline \multirow{2}{*}{$\begin{array}{c}\text { Types of } \\
\text { Solvent }\end{array}$} & \multicolumn{3}{c}{ Drying Method } \\
\cline { 2 - 4 } & Fresh & $\begin{array}{c}\text { Vacuum } \\
\text { Oven Drying }\end{array}$ & $\begin{array}{c}\text { Freeze } \\
\text { Drying }\end{array}$ \\
\hline Methanol & $3.84 \pm 0.33_{\mathrm{a}}{ }^{\mathrm{c}}$ & $38.26 \pm 1.65_{\mathrm{a}}{ }^{\mathrm{b}}$ & $54.46 \pm 1.24_{\mathrm{a}}{ }^{\mathrm{a}}$ \\
Ethanol & $2.61 \pm 0.33_{\mathrm{a}}{ }^{\mathrm{c}}$ & $32.68 \pm 0.06_{\mathrm{b}}{ }^{\mathrm{b}}$ & $45.40 \pm 1.01_{\mathrm{b}}{ }^{\mathrm{a}}$ \\
Water & $3.41 \pm 0.77_{\mathrm{a}}{ }^{\mathrm{c}}$ & $21.67 \pm 1.19_{\mathrm{c}}{ }^{\mathrm{b}}$ & $26.23 \pm 0.63_{\mathrm{c}}{ }^{\mathrm{a}}$ \\
\hline
\end{tabular}

Values $($ mean \pm SD) are average of three samples, analyzed individually in triplicate, different letter in superscript letters within the same row indicate significant $(\mathrm{P}<0.05)$ differences of means within the drying method; different letter in subscript letters within the same column indicate significant $(\mathrm{P}<0.05)$ differences of means within the solvents.

Antioxidant activity in most plants is mainly due to the TPC because it acts as the main contributor to antioxidant activity in herbs (Škerget et al., 2005). The highest TPC was recorded in freeze-dried samples. Freeze drying produces a crispier product than that of hot air drying (Pan et al., 2008). In the current study, freeze drying products also produced crispier texture than those of vacuum-oven drying products. The crispy texture may indicate the brittleness of the leaf tissues, which may result in rapid cell wall breakdown during milling and homogenization steps of the extraction procedure. These broken cell walls can release many phenolic compounds into the solvent (Hossain et al. 2010). Dorta et al. (2012) concluded that drying helps release a large percentage of bound phytochemical, that is, phenolic compounds, from the cellular structure, which made them considerably accessible during solvent extraction.

Fresh samples exhibited lower result than that of dried samples. This result revealed that the samples are largely prone to internal and external stresses, such as enzymatic degradation and oxidation by atmospheric oxygen, respectively (Hossain et al., 2010). Dilution effects may be the reason for the low antioxidant activity, TPC, and total flavonoid content (TFC) of compounds. This low performance was attributed that the enzymes in fresh leaves were still active, and they can lead to enzymatic degradation (Rabeta and Lin, 2015). High moisture content in fresh samples can be an indicator of high water activity. Enzymatic activity can only be inhibited at a certain point of water activity.

\subsection{Total flavonoid content}

Results showed that the highest total flavonoid contents among the samples were observed in freezedried samples with methanol extract $(950 \pm 17.32 \mathrm{mg}$ quercetin $/ \mathrm{g}$ ), freeze-dried samples with ethanol extract (743.33 $\pm 72.34 \mathrm{mg}$ quercetin $/ \mathrm{g}$ ), vacuum oven-dried samples with ethanol extract $(613.33 \pm 5.77 \mathrm{mg}$ quercetin/ g), vacuum oven-dried samples with methanol extract $(600 \pm 37.86 \mathrm{mg}$ quercetin $/ \mathrm{g})$, freeze-dried samples with water extract $(543.33 \pm 56.86 \mathrm{mg}$ quercetin $/ \mathrm{g})$, fresh samples with methanol $(506.67 \pm 68.07 \mathrm{mg}$ quercetin $/ \mathrm{g})$, fresh samples with ethanol $(483.33 \pm 11.55 \mathrm{mg}$ quercetin/ g), vacuum-oven dried samples with water extract $(286.67 \pm 60.28 \mathrm{mg}$ quercetin/g), and fresh samples with water extract $(140 \pm 36.06 \mathrm{mg}$ quercetin $/ \mathrm{g})$ sequentially (Table 3).

TFC assays resulted in almost the same trend as antioxidant activity assays (DPPH and FRAP). This similarity can be explained by that flavonoids possess free radical scavenging potential and antioxidant capacity (Naidu et al., 2016). According to Kumar and Pandey (2013), a large group of polyphenolic compounds consisted of flavonoids with a benzo- $\gamma$ -

Table 3. Total flavonoid content (mg quercetin/g) of the samples by using different extraction solvent and drying method

\begin{tabular}{lccc}
\hline \multirow{2}{*}{ Types of Solvent } & \multicolumn{4}{c}{ Drying Method } \\
\cline { 2 - 4 } & Fresh & Vacuum Oven Drying & Freeze Drying \\
\hline Methanol & $506.67 \pm 68.07_{\mathrm{a}}{ }^{\mathrm{c}}$ & $600.00 \pm 37.86_{\mathrm{a}}{ }^{\mathrm{b}}$ & $950.00 \pm 17.32_{\mathrm{a}}{ }^{\mathrm{a}}$ \\
Ethanol & $483.33 \pm 11.55_{\mathrm{a}}{ }^{\mathrm{c}}$ & $613.33 \pm 5.77_{\mathrm{b}}{ }^{\mathrm{b}}$ & $743.33 \pm 72.34_{\mathrm{b}}{ }^{\mathrm{a}}$ \\
Water & $140.00 \pm 36.06_{\mathrm{b}}{ }^{\mathrm{c}}$ & $286.67 \pm 60.28_{\mathrm{c}}{ }^{\mathrm{b}}$ & $543.33 \pm 56.86_{\mathrm{c}}{ }^{\mathrm{a}}$ \\
\hline
\end{tabular}

Values (mean \pm SD) are average of three samples, analyzed individually in triplicate, different letter in superscript letters within the same row indicate significant $(\mathrm{P}<0.05)$ differences of means within the drying method; different letter in subscript letters within the same column indicate significant $(\mathrm{P}<0.05)$ differences of means within the solvents. 
pyrone structure are widely present in plants. High antioxidant activity in green leafy vegetables is partially due to the presence of flavonoids (Hue et al., 2012). The consumption of flavonol, that is, quercetin, which is rich in onions and/or apples, reduces the risk of prostate, lung, stomach, and breast cancer (Kumar and Pandey, 2013)

TPC and TFC assay results showed almost the same trend, with the freeze-dried sample with methanol extract exhibiting the highest TPC and TFC; by contrast, fresh sample with water extract displayed the lowest TPC and TFC. Flavonoid is the largest group of plant phenols. Do et al. (2014) demonstrated a strong correlation (0.923) between polyphenolic contents (TPC and TFC) in Limnophila aromatica plant. This study supported the result that flavonoid is the major compound found in the phenolic group. The significant increase $(\mathrm{P}<0.05)$ in flavonoid content in fresh, freeze-dried, and vacuum oven-dried samples may be attributed to the formation of many flavonoid compounds due to the response to moisture loss during drying (Rabeta and Lai, 2013).

\subsection{Antioxidant activity assays (DPPH and FRAP)}

The percent inhibition of DPPH radical reflects the antioxidant activity of the extracts (Alothman et al., 2009b). The percent inhibition values of DPPH and FRAP showed a relatively wide variation among the drying samples and solvent types. In addition, the percent inhibition of DPPH ranged from $6.09 \pm 0.47 \%$ in fresh sample with water extract to $92.60 \pm 0.58 \%$ in freeze -dried sample with methanol extract (Table 4). The FRAP values ranged from $7.62 \pm 1.09 \mu \mathrm{mol} \mathrm{FeII/g}$ in fresh samples with water extract to $1,160.95 \pm 15.80 \mu \mathrm{mol}$ $\mathrm{FeII} / \mathrm{g}$ in freeze-dried sample with methanol extract (Table 5). Both assays showed the same trend of result with the highest antioxidant activity observed in freezedried sample with methanol extract and the lowest from fresh samples with water extract. In general, a significant difference $(\mathrm{P}<0.05)$ was observed among the fresh, vacuum oven-dried, and freeze-dried samples and among the three types of solvent. However, no significant difference $(\mathrm{P}>0.05)$ was observed among fresh samples exposed to three different types of solvent.
Table 4. DPPH inhibitions (\%) of the samples by using different extraction solvent and drying method

\begin{tabular}{lccc}
\hline \multirow{2}{*}{$\begin{array}{l}\text { Types of } \\
\text { Solvent }\end{array}$} & \multicolumn{3}{c}{ Drying Method } \\
\cline { 2 - 4 } & Fresh & $\begin{array}{c}\text { Vacuum- } \\
\text { Oven Drying }\end{array}$ & Freeze Drying \\
\hline Methanol & $9.10 \pm 0.23_{\mathrm{a}}{ }^{\mathrm{c}}$ & $66.96 \pm 1.73_{\mathrm{a}}^{\mathrm{b}}$ & $92.60 \pm 0.58_{\mathrm{a}}{ }^{\mathrm{a}}$ \\
Ethanol & $6.86 \pm 0.50_{\mathrm{a}}{ }^{\mathrm{c}}$ & $52.09 \pm 3.61_{\mathrm{b}}{ }^{\mathrm{b}}$ & $79.43 \pm 0.68_{\mathrm{b}}{ }^{\mathrm{a}}$ \\
Water & $6.09 \pm 0.47_{\mathrm{a}}{ }^{\mathrm{c}}$ & $37.11 \pm 0.28_{\mathrm{c}}{ }^{\mathrm{b}}$ & $42.55 \pm 0.19_{\mathrm{c}}{ }^{\mathrm{a}}$ \\
\hline
\end{tabular}

Values (mean $\pm \mathrm{SD}$ ) are average of three samples, analyzed individually in triplicate, different letter in superscript letters within the same row indicate significant $(\mathrm{P}<0.05)$ differences of means within the drying method; different letter in subscript letters within the same column indicate significant $(\mathrm{P}<0.05)$ differences of means within the solvents.

Veronezi et al. (2014) reported $31 \%$ of antioxidant activity of basil by using DPPH assay. Additionally, $73.75 \%$ of DPPH inhibition in Thai basil was reported by Naidu et al. (2016). Both of these previous results are in the range of the current study finding. Nonetheless, the value of percentage of inhibition varies in each study due to several factors, such as temperature, $\mathrm{pH}$, duration during storage, and type of solvent used (Arabshahi and Urooj, 2007).

Freeze-dried samples showed the highest antioxidant activities for both FRAP and DPPH assays. The same finding was reported by Wong et al. (2010); they indicated that freeze-dried samples of Alpinia species leaves can preserve antioxidant properties. Freeze-drying sample of leaves and berries of Cayratia trifolia or lakom also yields the highest antioxidant activity among vacuum-oven dried samples (Rabeta and Lin, 2015).

The high antioxidant activity in freeze-drying method may be due to a considerably low temperature $\left(-50^{\circ} \mathrm{C}\right)$ during moisture removal. Such low temperature during the drying process results in the constrained enzymatic degradation of antioxidant compounds (Wong et al., 2010). However, the antioxidant activity of vacuum-oven dried sample was significantly lower than that of freeze-dried samples, but the value was still in a high range. The lower antioxidant activity in vacuum oven-dried sample than that of freeze-dried samples may be due to the thermal drying, where fresh samples were dried at $30^{\circ} \mathrm{C}$ for 4 days compared with those freezedried at $-50^{\circ} \mathrm{C}$ for 3 days. The long duration of drying 
process under thermal environment may lead to the degradation of antioxidants, such as total phenols, thereby affecting their antioxidant activity (Mediani et al., 2014). Moreover, freeze drying and vacuum oven drying carried out under vacuumed environment, that is, without oxygen, help retard the potential oxidation; consequently, antioxidant compounds are preserved (Leusink et al., 2010).

Solvent extraction process plays a vital role in isolating target compounds, such as polyphenol. The solvent characteristics, such as polarity, $\mathrm{pH}$, temperature, and concentration, are key factors affecting the solubility of phenolic compounds in the solvent (Tabart et al., 2007). In the present study, aqueous methanol solvent was considered the most suitable solvent for extracting phenolic compounds. Ethanol extract also showed a good antioxidant activity, which was still significantly different $(\mathrm{P}<0.05)$ from that of the aqueous methanol extract. These results are in good agreement with the results of a previous study, where methanol solvent extract produces the highest amount of total phenols in mulberry (Arabshahi and Urooj, 2007).

Although water displayed higher PI than those of ethanol and methanol, it was the weakest extraction solvent among the three because of low results in antioxidant activity assays. Water or pure ethanol and methanol exhibit low efficiency in extracting polyphenol compounds (Brahmi et al., 2012). This finding can be explained by that water extraction only possesses a single solvent compared with aqueous methanol and ethanol, which consist of two types of solvents. Given the incorporation of two types of solvents or more, the solvent system can extract phenolic substances from low, medium, or high polarity (Spigno et al., 2007). Solvent polarity can also be increased by increasing the water proportion. In addition, water can cause swelling of plant material, thereby increasing the penetration ability of solvent into the solid matrix and the extractability of phenolic compound (Brahmi et al., 2012).

\section{Conclusion}

The total phenolic content (TPC) and total flavonoid content (TFC) assays showed almost the same values in the freeze-dried sample of methanol extract as it exhibited the highest TPC and TFC values- whereas the water extract showed only $26.23 \pm 0.63 \mathrm{mg}$ gallic acid $/ \mathrm{g}$ and $543.33 \pm 56.86 \mathrm{mg}$ quercetin $/ \mathrm{g}$, respectively. On the contrary, fresh sample with water extract displayed the lowest TPC and TFC. Both FRAP and DPPH assays showed the same trend of result with the highest antioxidant activity observed in freeze-dried sample with methanol extract and the lowest from fresh samples with water extract.

\section{Conflict of interest}

We declare that we have no conflict of interest.

\section{Acknowledgment}

The research work is supported by Food Technology Division, School of Industrial Technology, Universiti Sains Malaysia.

\section{References}

Agoreyo, B.O., Akpiroroh, O., Orukpe, O.A., Osaweren, O.R. and Owabor, C.N. (2011). The effects of various drying methods on the nutritional composition of Musa paradisiaca, Dioscorea rotundata and Colocasia esculenta. Asian Journal of Biochemistry, 6 (6), 458-464. https://doi.org/10.3923/ ajb.2011.458.464

Agunbiade, S.O., Ojezele, M.O. and Alao, O.O. (2015). Evaluation of the nutritional, phytochemical compositions and likely medicinal benefits of Vernomia amygdalina, Talinum triangulare and Ocimum basilicum leafy-vegetables. Advances in Biological Research, 9(3), 447-452.

Alothman, M., Bhat, R. and Karim, A. (2009a). UV Radiation-Induced Changest of Antioxidant Capacity of Fresh-Cut Tropical Fruits. Innovative Food Science and Emerging Technology, 10(4), 512-516. https:// doi.org/10.1016/j.ifset.2009.03.004

Alothman, M., Bhat, R. and Karim, A.A. (2009b). Antioxidant capacity and phenolic content of selected tropical fruits from Malaysia, extracted with different solvents. Food Chemistry, 115(3), 785-788. https:// doi.org/10.1016/j.foodchem.2008.12.005

Antolovich, M., Prenzler, P.D., Patsalides, E., McDonald, S. and Robards, K. (2002). Methods for testing antioxidant activity. Analyst, 127(1), 183-198. https:// doi.org/10.1039/b009171p

Arabshahi, D.S. and Urooj, A. (2007). Antioxidant properties of various solvent extracts of mulberry (Morus indica L.) leaves. Food Chemistry, 102(4), 1233-1240. https://doi.org/10.1016/ j.foodchem.2006.07.013

Benzie, I.F. and Strain, J.J. (1996). The ferric reducing ability of plasma (FRAP) as a measure of "antioxidant power": the FRAP assay. Analytical Biochemistry, 239(1), 70-76. https://doi.org/10.1016/ j.foodchem.2006.07.013

Brahmi, F., Madani, K., Dahmoune, F., Rahmani, T., Bousbaa, K., Oukmanou, S. and Chibane, M. (2012). Optimization of Solvent Extraction Of Antioxidants 
(Phenolic Compounds) From Algerian Mint (Mentha spicata L). Pharmacognosy Communications, 2(4), 72 $-86$.

Ch, M.A., Naz, S.B., Sharif, A., Akram, M. and Saeed, M.A. (2015). Biological and Pharmacological Properties of the Sweet Basil (Ocimum basilicum). British Journal of Pharmaceutical Research,7(5), 330 -339. https://doi.org/10.9734/BJPR/2015/16505

Do, Q.D., Angkawijaya, A.E., Tran-Nguyen, P.L., Huynh, L.H., Soetaredjo, F.E., Ismadji, S. and Ju, Y.H. (2014). Effect of extraction solvent on total phenol content, total flavonoid content, and antioxidant activity of Limnophila aromatica. Journal of Food and Drug Analysis, 22(3), 296-302. https:// doi.org/10.1016/j.jfda.2013.11.001

Dorta, E., Lobo, M.G. and González, M. (2012). Using drying treatments to stabilise mango peel and seed: Effect on antioxidant activity. LWT-Food Science and Technology, 45(2), 261-268. https://doi.org/10.1016/ j.lwt.2011.08.016

Hossain, M.B., Barry-Ryan, C., Martin-Diana, A.B. and Brunton, N.P. (2010). Effect of drying method on the antioxidant capacity of six Lamiaceae herbs. Food Chemistry, 123(1), 85-91. https://doi.org/10.1016/ j.foodchem.2010.04.003

Hue, S.M., Boyce, A.N. and Chandran, S. (2012). Antioxidant Activity, Phenolic and Flavonoid Contents in the Leaves of Different Varieties of Sweet Potato (Ipomoea batatas). Australian Journal of Crop Science, 6(3), 375-380.

Kamtekar, S., Keer, V. and Patil, V. (2014). Estimation of Phenolic content, Flavonoid content, Antioxidant and Alpha amylase Inhibitory Activity of Marketed Polyherbal Formulation. Journal of Applied Pharmaceutical Science, 4(9), 061-065.

Kumar, S. and Pandey, A.K. (2013). Chemistry and biological activities of flavonoids: an overview. The Scientific World Journal, 2013, 162750. http:// dx.doi.org/10.1155/2013/162750

Leusink, G.J., Kitts, D.D., Yaghmaee, P. and Durance, T. (2010). Retention of antioxidant capacity of vacuum microwave dried cranberry. Journal of Food Science, 75(3), 311-316. https://doi.org/10.1111/j.17503841.2010.01563.x

Marwat, S.K., Khan, M.A., Fazal-ur-Rehman, A.H., Shoaib, M. and Shah, M.A. (2011). Interpretation and Medicinal Potential of Ar-Rehan (Ocimum basilicum L.) A Review. American-Eurasian Journal of Agricultural and Environmental Science, 10, 478-484.

Mediani, A., Abas, F., Tan, C.P. and Khatib, A. (2014). Effects of different drying methods and storage time on free radical scavenging activity and total phenolic content of Cosmos caudatus. Antioxidants, 3(2), 358370. https://doi.org/10.3390/antiox3020358

Morris, A., Barnett, A. and Burrows, O. (2004). Effect of processing on nutrient content of foods. Cajanus, 37 (3), 160-164.

Naidu, J.R., Ismail, R.B. and Sasidharan, S. (2016). Chemical Profiling and Antioxidant Activity of Thai Basil (Ocimum basilicum). Journal of Essential Oil Bearing Plants, 19(3), 750-755. https:// doi.org/10.1080/0972060X.2013.793989

Ogunlakin, G.O., Oke, M.O., Babarinde, G.O. and Olatunbosun, D.G. (2012). Effect of drying methods on proximate composition and physico-chemical properties of cocoyam flour. American Journal of Food Technology, 7(4), 245-250. https:// doi.org/10.3923/ajft.2012.245.250

Ojo, A., Abiodun, O.A., Odedeji, J.O. and Akintoyese, O.A. (2014). Effects of Drying Methods on Proximate and Physico-chemical Properties of Fufu Flour Fortified with Soybean. British Journal of Applied Science and Technology, 4(14), 2079-2089. https:// doi.org/10.9734/BJAST/2014/8984

Pan, Z., Shih, C., McHugh, T.H. and Hirschberg, E. (2008). Study of Banana Dehydration Using Sequential Infrared Radiation Heating and FreezeDrying. LWT-Food Science and Technology, 41(10), 1944-1951. https://doi.org/10.1016/j.lwt.2008.01.019

Rabeta, M.S. and Lai, S.Y. (2013). Effects of Drying, Fermented and Unfermented Tea of Ocimum tenuiflorum Linn. on the Antioxidant Capacity. International Food Research Journal, 20(4), 16011608.

Rabeta, M.S. and Lin, S.P. (2015). Effects of Different Drying Methods on the Antioxidant Activities of Leaves and Berries of Cayratia trifolia. Sains Malaysiana, 44(2), 275-280. https://doi.org/10.17576/ jsm-2015-4402-16

Razak, N.A., Shaari, A.R., Nat, A.F.A. and Abdullah, S. (2014). Effect of initial leaf moisture content on the herbal quality parameter of Orthosiphon stamineus dried leaf during storage. International Journal of Agriculture Innovations and Research, 2(6), 11311136.

Škerget, M., Kotnik, P., Hadolin, M., Hraš, A.R., Simonič, M. and Knez, Ž. (2005). Phenols, proanthocyanidins, flavones and flavonols in some plant materials and their antioxidant activities. Food Chemistry, 89(2), 191-198.

j.foodchem.2004.02.025

https://doi.org/10.1016/

Sospedra, I., Soriano, J.M. and Mañes, J. (2010). Assessment of the microbiological safety of dried spices and herbs commercialized in Spain. Plant 
Foods for Human Nutrition, 65(4), 364-368. https:// doi.org/10.1007/s11130-010-0186-0

Spigno, G., Tramelli, L. and De Faveri, D.M. (2007). Effects of extraction time, temperature and solvent on concentration and antioxidant activity of grape marc phenolics. Journal of Food Engineering, 81(1), 200208. https://doi.org/10.1016/j.jfoodeng.2006.10.021

Tabart, J., Kevers, C., Sipel, A., Pincemail, J., Defraigne, J.O. and Dommes, J. (2007). Optimisation of Extraction of Phenolics and Antioxidants from Black Currant Leaves and Buds and of Stability During Storage. Food Chemistry, 105(3), 1268-1275. https:// doi.org/10.1016/j.foodchem.2007.03.005

Tewari, D., Sah, A.N., Pandey, H.K. and Meena, H.S. (2012). A Review on Phytoconstituents of Ocimum (Tulsi). International Journal of Ayurvedic Medicine, 3(1), 1-9

Thorat, I.D., Jagtap, D.D., Mohapatra, D., Joshi, D.C., Sutar, R.F. and Kapdi, S.S. (2013). Antioxidants, Their Properties, Uses in Food Products and Their Legal Implications. International Journal of Food Studies, 2(1),81-104. https://doi.org/10.7455/ ijfs/2.1.2013.a7

Veronezi, C.M., Costa, T. and Jorge, N. (2014). Basil (Ocimum basilicum L.) as a Natural Antioxidant. Journal of Food Processing and Preservation, 38(1), 255-261. https://doi.org/10.1111/j.17454549.2012.00771.x

Wong, S.K., Wong, L.F., Lim, Y.Y. and Chan, E.W.C. (2010). Effects of drying treatments on the antioxidant properties of leaves and teas of Alpinia species. Journal of Tropical Medicinal Plants, 11(2), 97-105. 